\title{
African four-striped grass mice (Rhabdomys pumilio), a diurnal-crepuscular muroid rodent, in the behavioral laboratory
}

\author{
DONALD A. DEWSBURY \\ Department of Psychology, University of Florida, Gainesville, Florida 32611 \\ and \\ WILLIAM W. DAWSON \\ Departments of Ophthalmology, Physiology, and Psychology, University of Florida, \\ Gainesville, Florida 326II
}

\begin{abstract}
African four-striped grass mice, Rhabdomys pumilio, are potentially valuable animals for laboratory studies of behavior. In nature, they live in the grasslands of much of Africa. In the laboratory, striped mice adapt well to a number of behavioral testing situations. Ten male grass mice tested in running wheels displayed a mean of approximately 10,000 revolutions per day, with a diurnal-crepuscular pattern characterized by sharp peaks near the time of light onset and offset and a generally greater level of wheel running in light than in darkness. The retinal anatomy of this species is characterized by a cone-like organization of the outer segment layer and unusual thickness of the inner plexiform layer, suggesting an unusual high amount of retinal data processing for a muroid rodent. The copulatory pattern of $R$. pumilio is characterized by no lock, no intravaginal thrusting, multiple intromissions preceding ejaculation, and multiple ejaculations. The number of intromissions preceding the first ejaculation is unusually high, and postejaculatory intervals are unusually long. Grass mice display intermediate levels of open-field activity, but little climbing or digging.
\end{abstract}

African four-striped grass mice appear suitable for numerous laboratory studies of behavior. They display a diurnal-crepuscular activity pattern. For this reason, they may be of great utility for researchers in the rapidly growing area of biological rhythms (e.g., Rusak $\&$ Zucker, 1975). There is reason to expect diurnal and nocturnal species to generate different orderly functional relationships in such studies (Aschoff, 1960). Studies of rodent thythms have emphasized diurnal sciurid rodents and nocturnal muroid rodents. Investigation of diurnal muroids would provide a valuable addition. Nocturnal rodents with poor visual acuity have often been subjects in studies of visual discrimination learning and other visual phenomena. The diurnal Sciuridae are extremely difficult to breed, somewhat difficult to maintain, and generally hard to handle. By contrast, four-striped grass mice appear adapted for the processing of more visual information than most nocturnal rodents, yet are relatively small and easy to maintain in the laboratory. These animals, like many species of muroid rodents, perform readily in other test situations and may be useful in the study of a broad range of problems (cf. Dewsbury, 1974).

This research was supported by Grant BNS78-05173 from the National Science Foundation. We thank curator Clyde A. Hill of the Zoological Society of San Diego for providing the initial breeding stock of Rhabdomys pumilio and encouraging their study.

\section{GENERAL CHARACTERISTICS}

Four-striped grass mice, Rhabdomys pumilio, are classified in the order Rodentia, suborder Myomorpha, superfamily Muroidea, family Muridae, and subfamily Murinae (Morris, 1965). This places them in the same subfamily as the more common laboratory species, Rattus norvegicus and Mus musculus.

$R$. pumilio are characterized by four black stripes that run the length of the body and a pale middorsal line. They have a yellow to gray-brown ground color with a tail that is black above and light brown below (Delany \& Neal, 1966) (Figure 1).

The natural distribution of $R$. pumilio encompasses a wide area of sub-Saharan Africa, where they are often quite common (Delany \& Neal, 1966; Roberts, 1951; Shortridge, 1934). $R$. pumilio typically live in grasslands, especially at high altitudes (Taylor \& Green, 1976). The mice are usually found in runways under tall grass, the ground cover providing important protection from arboreal predators. Nests are built of grasses above ground, have a single entrance hole, and are located at the end of a covered runway (Choate, 1972). In areas inhabited by humans, the mice often live near vegetable gardens, although they generally do not move into houses themselves (Shortridge, 1934). The diet consists primarily of seeds, Acacia pods and seeds, and berries, although the mice have been known to eat snails, insects 


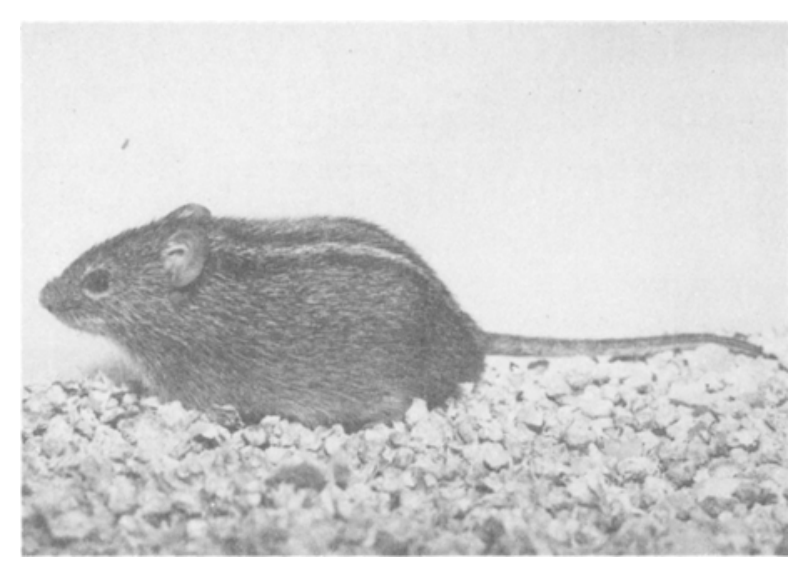

Figure 1.

and eggs, and nestlings of birds (Delany \& Neal, 1966; Nel, 1975).

In some areas, such as savannas, striped mice are rather solitary, with males occupying well separated areas (Choate, 1972). In other areas, such as in the Kalihari, the mice are more social, living in clusters in relatively close proximity to each other (Nel, 1975).

Striped mice are seasonal breeders, with the onset of breeding apparently tied to rainfall levels and to dietary characteristics (Taylor \& Green, 1976). They have a postpartum estrus (Choate, 1972). Mean litter size has been reported as 5.0 (range $=3.9)(\mathrm{Nel}, 1975)$ and 5.4 (range $=2-10$ ) (Taylor \& Green, 1976).

Captive colonies are known to exist at the San Diego zoo, the National Zoo, Washington, D. C., Brookfield Zoo, Chicago, Illinois, the Houston zoo, Cincinnati zoo, Philadelphia zoo, Frankfurt zoo, the Department of Biological Sciences, Northwestern University, and the Department of Biological Sciences, University of Minnesota.

\section{MAINTENANCE AND BREEDING IN THE LABORATORY}

A colony of $R$. pumilio diminutus was established at the University of Florida with the purchase of three adult males and three adult females from the Zoological Society of San Diego. They were from stock captured on a farm near Nakuru, Kenya.

In our laboratory, animals are kept on a reversed 16:8 photoperiod. Red lights shine at all times. Animals are generally kept in Maryland Plastics cages measuring either $48 \times 27 \times 13 \mathrm{~cm}$ or $29 \times 19 \times 13 \mathrm{~cm}$. We have been unable to breed animals in cages of these sizes, however, and have used larger plastic cages, measuring $51 \times 41 \times 22 \mathrm{~cm}$. Cage bottoms are lined either with wood shavings or with ground corn cob (San-i-cel) as bedding material. Breeding pairs are provided with large glass tumblers that serve as nesting jars. Individual animals thrive on Purina laboratory animal chow Type 5001 and water. The diets of breeding pairs have been supplemented with fruit, such as apples and oranges, lettuce, and millet seeds. Nonbreeding animals are generally housed individually, although female littermates may be housed in groups. Males, even littermates, tend to be intolerant of group housing, and severe wounds and death appear common (see also Choate, 1972). For that reason, males are moved to individual cages when approximately 35 days of age. A mixed-sex group of $R$. pumilio thrives in a large exhibit cage in the children's zoo of the San Diego zoo.

Striped mice are relatively easy to handle, but they will bite, and gloves are routinely used. Although typical of nondomesticated rodents, they are much faster in their movements than most domesticated species. For this reason, cages are opened only when in large enclosures that prevent escape. When handled, animals almost always emit a high-pitched vocalization.

We have succeeded in breeding only four pairs of $R$. pumilio. We and others have experienced some difficulty in initiating breeding. It is likely that this can be improved by dietary supplements (see Taylor \& Green, 1976). However, once initiated, breeding is quite reliable. Our breeding pairs have produced a total of 22 litters, with a range of 1.14 litters per pair. One pair produced 14 litters in the course of 348 days, with a mean interlitter interval of 24.8 days. The 22 litters have included 57 males and 54 females, for a mean litter size of 5.0 (range $=3-7$ ). The mean body weights at 90 days of age for 13 males were $45.0 \mathrm{~g}(\mathrm{SE}=1.3)$ and for 12 females, $39.4 \mathrm{~g}(\mathrm{SE}=1.1)$. Offspring typically are weaned at about 14 days of age; otherwise, they escape through the lids of Maryland Plastic Series 70 cages.

\section{ACTIVITY PATTERNS}

Reports of field studies are unanimous with regard to the diurnal activity pattern of this species (Choate, 1972; Delany \& Neal, 1966; Nel, 1975; Roberts, 1951; Shortridge, 1934; Taylor \& Green, 1976). Choate (1972) studied activity rhythms in the laboratory with animals maintained on a 12:12 photoperiod of white light, with red light shining during the dark phase. $R$. pumilio was more active in the light phase than in the dark. However, the period of activity extended into the dark phase on some occasions. Activity began in apparent anticipation of the onset of white light. Because Choate (1972) reported only part of his data and his methods are not clearly described, a study of the diurnal patterning of wheel running was undertaken in this laboratory.

\section{Method}

Subjects were 10 male $R$. pumilio, 60-90 days of age when first placed in running wheels. The running wheels were standard Wahmann Model LC-34 wheels.

Mice were maintained on a 16:8 reversed photoperiod, with white fluorescent room lights going off at $1000 \mathrm{~h}$ and on at $1800 \mathrm{~h}$. There was no red light. In order to familiarize the mice with the wheel running apparatus and attain a stable baseline of activity, mice were first placed in one set of wheels for a period of 14 days with no data recorded. They were then transferred to 


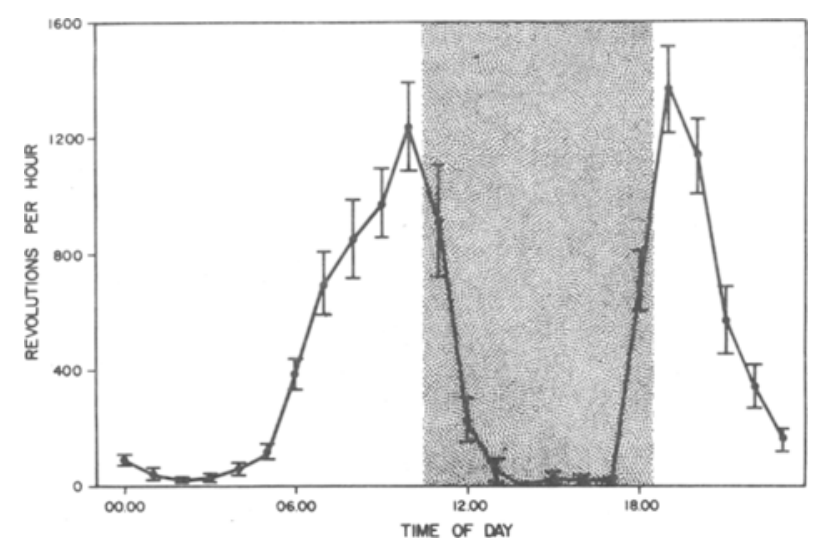

Figure 2.

a second set of wheels in the same room that were connected to a bank of Stoelting printout counters set to record the number of wheel revolutions every $1 \mathrm{~h}$. After 1 day of habituation in the new cages, data were recorded for a period of 14 days.

\section{Results}

The mice registered a mean of 10,074 counts per day. The temporal patterning of this wheel running is portrayed in Figure 2. This pattern might best be described as diurnal-crepuscular. There are two sharp peaks near the times of light onset and offset. In both cases, there is a clear-cut increase in wheel running prior to the change in lighting conditions. Although there was relatively little activity during the light phase between $0000 \mathrm{~h}$ and $0500 \mathrm{~h}$, the activity level was generally greater in light than in dark. There were 2.06 times as many counts per hour during the light phase as during the dark.

\section{Discussion}

As noted by Choate (1972), R. pumilio appear to display more nocturnal activity in the laboratory than has been reported for the field. Nevertheless, they still display approximately twice as many revolutions per hour in light as in dark. This difference is dwarfed by the two sharp peaks that begin prior to the change in lighting conditions and decline shortly thereafter. The extent to which the control of this rhythm is endogenous has yet to be determined.

\section{RETINAL ANATOMY}

A species with diurnal habits would be expected to evolve a visual system differing from those of the more common nocturnal muroid rodents. Studies of the anatomy of the retina of striped mice were conducted to determine the extent to which this is the case.

\section{Method}

Retinal tissue was prepared by intracardiac perfusion of buffered neutral formalin. The epon embedded sections were cut at 2 microns from tissue blocks of the geometric retinal center.

\section{Results}

The anatomy of the retina of a laboratory rat (Rattus norvegicus, Wistar strain) and a grass mouse are compared in Figure 3. The major features of the retina of grass mice are the long structures in the receptor layer; these appear rod-like in organization, although some cone-like structures were seen. Although the outer nuclear layer of the grass mouse (Figure $3 \mathrm{~A}$ ) is thinner than that of the rat, the inner plexiform layer is remarkable in that it is approximately four times the thickness of the corresponding layer in the laboratory rat (Figure 3B). Ganglion cell nuclei are more numerous in the grass mouse but did not stain deeply, suggesting a different biochemical structure from that of the laboratory rat.

\section{Discussion}

The organization of the outer segment layer, together with the remarkable thickness of the inner plexiform layer of grass mice, suggest that there is an unusually large amount of retinal data processing for a muroid rodent present in grass mice. This is consistent with the diurnal habits of these animals and suggests that they may be interesting animals in which to study problems relating vision to behavior.

\section{COPULATORY BEHAVIOR}

A major focus of activity in this laboratory is on comparative studies of copulatory behavior (see Dewsbury, 1975). Comparative studies of copulatory behavior among the muroid rodents are designed to study the evolution and adaptive significance of patterns of reproductive behavior.

\section{Method}

Subjects were 15 male-female pairs of $R$. pumilio. An additional three pairs were tested, but they mated inconsistently.

Tests were conducted in the males' home cages $(48 \times 27 \times$ $13 \mathrm{~cm}$ ) and behavioral events were recorded on an EsterlineAngus operations recorder.

Females were injected with $.08 \mathrm{mg}$ of estradiol benzoate 3 days before testing and $.8 \mathrm{mg}$ progesterone on the morning of tests. This produced behavioral receptivity in most females with excellent reliability and also served as an efficient contraceptive.

Tests were begun at approximately $1430 \mathrm{~h}$ and were conducted in red light. An injected female was introduced into a male's home cage. If copulation was not initiated, the test was terminated and discounted. If copulation was initiated, tests were continued until attainment of a satiety criterion of $30 \mathrm{~min}$ with no copulations. Three positive tests were conducted for each male-female pair, with a minimum of 2 weeks separating successive tests.

The basic elements of the copulatory behavior of $R$. pumilio are identical to those of laboratory rats (Beach \& Jordan, 1956) and many other species. Three primary events can be distinguished behaviorally: mounts (with no apparent vaginal intromission), intromissions (with vaginal intromission but no sperm transfer), and ejaculations (with vaginal intromission and sperm transfer). These patterns occur in orderly bouts, or "series," with each series terminated by an ejaculation. The standard measures of copulatory behavior used with laboratory rats were applied to grass mice: mount latency (ML)-time in 


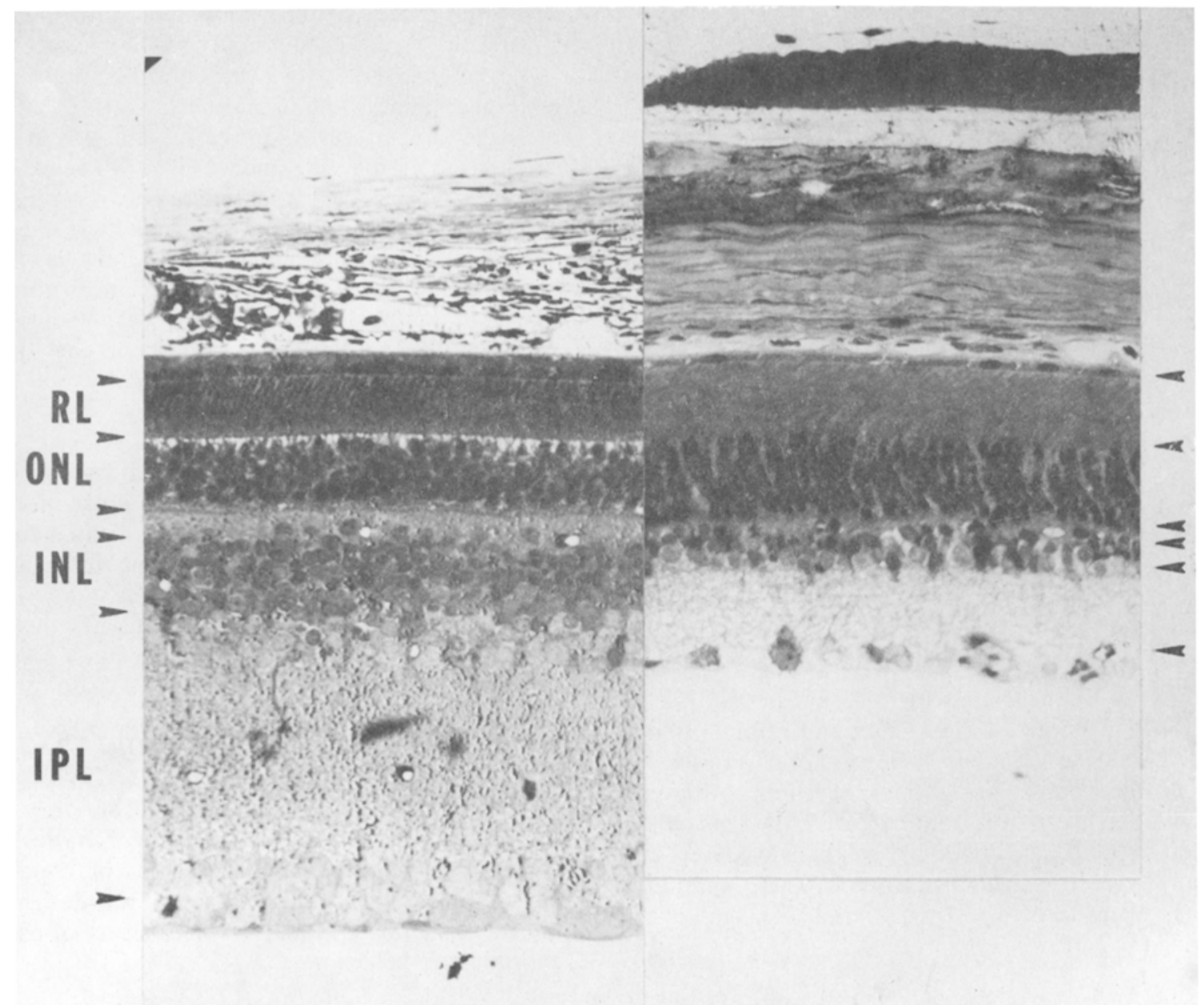

Figure 3.

seconds from the start of a test to the first mount or intromission; intromission latency (IL)-time in seconds from the start of a test to the first intromission; ejaculation latency (EL)-time. in seconds from the first intromission of a series until ejaculation; intromission frequency (IF)-the number of intromissions in a series; mount frequency (MF)-number of mounts in a series; mean interintromission interval (MIII)-mean interval in seconds separating the intromissions of a series; postejaculatory interval (PEI)-time in seconds from an ejaculation until the next intromission; and ejaculation frequency (EF)-the number of ejaculations in a test.

\section{Results}

The results of the study of copulatory behavior are presented in Table 1. Scores from all pairs are equally weighted. The first intromission occurred approximately 15 min after the introduction of the female. A mean of 3.3 ejaculations preceded attainment of the satiety criterion. More than half of the tests did not go beyond three series; only seven tests continued for five series.

The first series occupied a mean of approximately $13 \mathrm{~min}$, with 27 intromissions spaced about $.5 \mathrm{~min}$ apart. Later series were shorter, as they were character- ized by both fewer intromissions and shorter MIIIs. The first PEI was $13 \mathrm{~min}$, with later PEIs longer than the first.

\section{Discussion}

$R$. pumilio display the rather common copulatory Pattern 13 described by Dewsbury (1972), which includes no lock (mechanical tie between penis and vagina), no intravaginal thrusting, multiple intromission prerequisite to ejaculation, and multiple ejaculations. The copulatory behavior is unusual only in that grass mice display a rather large number of intromissions prior to the first ejaculation and relatively long PEIs. As the mice respond reliably to injections of exogenous hormones, studies of copulatory behavior are feasible and should progress with relative ease.

\section{MISCELLANEOUS BEHAVIORAL PATTERNS}

One of the activities of this laboratory is the collection of comparative data on the behavioral patterns of a 
Table 1

Mean Scores of Copulatory Behavior for 15 Pairs of Rhabdomys pumilio in Three Tests per Pair

\begin{tabular}{|c|c|c|c|c|c|c|}
\hline \multirow[b]{2}{*}{$\begin{array}{l}\text { Mea- } \\
\text { sure }\end{array}$} & \multicolumn{6}{|c|}{ Series } \\
\hline & 1 & 2 & 3 & 4 & 5 & $\begin{array}{l}\text { Incom- } \\
\text { plete }\end{array}$ \\
\hline ML & 667.6 & & & & & \\
\hline IL & 929.4 & & & & & \\
\hline EL & 789.0 & 302.5 & 246.4 & 255.4 & 427.2 & (2043.3) \\
\hline IF & 27.0 & 12.7 & 12.6 & 14.0 & 12.5 & (33.7) \\
\hline MF & 15.8 & 6.7 & 4.5 & 6.5 & 14.6 & $(15.0)$ \\
\hline MIII & 31.9 & 25.0 & 19.3 & 18.6 & 32.8 & \\
\hline PEI & 806.8 & 879.2 & 1009.2 & 1034.7 & & \\
\hline $\mathrm{EF}$ & 3.3 & & & & & \\
\hline $\mathrm{N}$ & 45 & 42 & 34 & 19 & 7 & 4 \\
\hline
\end{tabular}

variety of species of muroid rodents. $R$. pumilio have been used in several of these studies. Open-field behavior in 12 species of muroid rodents was reported by Wilson, Vacek, Lanier, and Dewsbury (1976). As a supplement to that research, Webster, Baumgardner, and Dewsbury (1979) have collected data on eight additional taxa using similar methods. Ten adult male striped mice entered a mean of 441.0 squares in 10 -min tests. This represents an intermediate level of activity for muroid rodents. Behavioral patterns in the open field were categorized using an operations recorder. There was much individual variability in this species. Overall, there was a rather high level of freezing, with $30.1 \%$ of the time spent in such inactivity. Only $46 \%$ of the time was spent in locomotor-exploratory behavior. A mean of 3.2 fecal boli were deposited.

A comparative study of climbing behavior (Dewsbury, Lanier, \& Miglietta, in press) showed that striped mice have little inclination to climb a hardware cloth cone with horizontal dowel rod. Just one mouse climbed on the cone and, overall, the mean amount of time spent off the ground in 5-min tests was $2.4 \mathrm{sec}$. This is consistent with their nonarboreal behavior in the field.

In a comparative study of digging behavior that is in progress, striped mice display relatively little digging compared with species such as northern grasshopper mice (Onychomys leucogaster), which are burrow dwellers.

\section{CONCLUSION}

African striped grass mice are unusual muroid rodents in that they display a diurnal-crepuscular activity pattem and have a retina apparently adapted for much visual information processing. They respond readily in tests of copulatory and other behavioral patterns. Their small size, ease of maintenance, and various unique characteristics make them an interesting species for behavioral research.

\section{REFERENCES}

Aschoff, J. Exogenous and endogenous components in circadian rhythms. Cold Spring Harbor Symposium on Quantitative Biology, 1960, 25, 11-28.

BeAch, F. A., \& Jordan, L. Sexual exhaustion and recovery in the male rat. Quarterly Journal of Experimental Psychology, $1956,8,121-133$.

Choate, T. S. Behavioral studies on some Rhodesian rodents. Zoologica Africana, 1972, 7, 103-118.

Delany, M. J., \& Neal, B. R. A review of the Muridae (Order Rodentia) of Uganda. Bulletin of the British Museum (Natural History), 1966, 13, 295-355.

Dewsbury, D. A. Patterns of copulatory behavior in male mammals. Quarterly Review of Biology, 1972, 47, 1-33.

DewsBury, D. A. The use of muroid rodents in the psychology laboratory. Behavior Research Methods \& Instrumentation, 1974, 6, 301-308.

Dewsbury, D. A. Diversity and adaptation in rodent copulatory behavior. Science, 1975, 190, 947-954.

Dewsbury, D. A., Lanier, D. L., \& Miglietta, A. A laboratory study of climbing behavior in eleven species of muroid rodents. American Midland Naturalist, in press.

Morris, D. The mammals: A guide to living species. New York: Harper \& Row, 1965.

NEL, J. A. J. Aspects of the social ethology of some Kalahari rodents. Zeitschrift fur Tierpsychologie, 1975, 37, 322-331.

Rogents, A. The mammals of South Africa. New York: Hafner, 1951.

RusAK, B., \& ZuckeR, I. Biological thythms and animal behavior. Annual Review of Psychology, 1975, 26, 137-171.

Shortridge, G. C. The mammals of South West Africa. London: Heinemann, 1934.

TAYloR, K. D., \& Green, M. G. The influence of rainfall on diet and reproduction in four African rodent species. Journal of Zoology, London, 1976, 180, 367-389.

Webster, D. G., Baumgardner, D. J., \& Dewsbury, D. A. Open-field behavior in eight taxa of muroid rodents. Bulletin of the Psychonomic Society, 1979, 13, 90-92.

Wilson, R. C., Vacek, T., Lanier, D. L., \& Dewsbury, D. A. Open-field behavior in muroid rodents. Behavioral Biology, 1976, 17, 495-506.

(Received for publication November 16, 1978; revision accepted January $17,1979$. ) 